\title{
Antibody neutralization of cell-surface gC1qR/HABP1/SF2-p32 prevents lamellipodia formation and tumorigenesis
}

\author{
Beom-Chan Kim ${ }^{1,2}$, Hyun-Jung Hwang ${ }^{1,3}$, Hyoung-Tae An ${ }^{1,2}$, Hyun Lee ${ }^{1,2}$, Jun-Sub \\ Park $^{1,2}$, Jin Hong ${ }^{1,2}$, Jesang Ko ${ }^{1,2}$, Chungho Kim ${ }^{1}$, Jae-Seon Lee ${ }^{3}$, Young-Gyu Ko ${ }^{1,2}$ \\ ${ }^{1}$ Tunneling Nanotube Research Center, Korea University, Seoul, 02841, Korea \\ ${ }^{2}$ Division of Life Sciences, Korea University, Seoul, 02841, Korea \\ ${ }^{3}$ Department of Molecular Medicine, College of Medicine, Inha University, Incheon, 22212, Korea \\ Correspondence to: Young-Gyu Ko, email: ygko@korea.ac.kr \\ Keywords: gClqR, lamellipodia, cell migration, antibody, cancer \\ Received: January 07, $2016 \quad$ Accepted: May 28, $2016 \quad$ Published: June 24, 2016
}

\section{ABSTRACT}

We previously demonstrated that cell-surface gC1qR is a key regulator of lamellipodia formation and cancer metastasis. Here, we screened a monoclonal mouse antibody against gC1qR to prevent cell migration by neutralizing cell-surface gC1qR. The anti-gC1qR antibody prevented growth factor-stimulated lamellipodia formation, cell migration and focal adhesion kinase activation by inactivating receptor tyrosine kinases (RTKs) in various cancer cells such as A549, MDA-MB-231, MCF7 and HeLa cells. The antibody neutralization of cell-surface $\mathrm{gC1}$ qR also inhibited angiogenesis because the anti-gC1qR antibody prevented growth factor-stimulated RTK activation, lamellipodia formation, cell migration and tube formation in HUVEC. In addition, we found that A549 tumorigenesis was reduced in a xenograft mouse model by following the administration of the anti-gC1qR antibody. With these data, we can conclude that the antibody neutralization of cell-surface gC1qR could be a good therapeutic strategy for cancer treatment.

\section{INTRODUCTION}

The receptor for the globular head of complement subunit $\mathrm{Clq}, \mathrm{gClqR}$, is first identified as a binding molecule of $\mathrm{C} 1 \mathrm{q}$ and nuclear splicing factor (SF2-p32) $[1,2]$. Although $\mathrm{gClqR}$ is mainly localized in the mitochondria, it is also found on the cell-surface in various cell types such as 3T3-L1 adipocytes and A549 cells [3-7]. The cell-surface $\mathrm{gClqR}$ binds to extracellular matrix components such as hyaluronic acid, fibronectin and vitronectin [8-10]. For example, the cell-surface $\mathrm{gClqR}$ associates with hyaluronic acid, which is why it is also called hyaluronic acid-binding protein-1 (HABP1). In addition, the molecular association of $\mathrm{gClqR}$ with $\mathrm{Clq}$ leads to classical complement activation [11].

Previous studies have shown that the cell-surface $\mathrm{gClqR}$ could be a diagnostic marker and a new therapeutic target for cancer. The expression level of gClqR is highly induced in various human malignant tumors, such as lung, breast, ovary, endometrial and colon tumors, compared to their normal tissues [5, 12-14]. The gClqR expression level is inversely correlated with overall and tumor progression- free survival rate and is in proportion to the cisplatinresistance in ovarian cancer patients [12]. Notably, the cell-surface gC1qR levels increase in breast cancer cells after tumor xenograft and gradually increased with cancer progression in an MCF10A cancer progression model [5].

Cell migration is a critical process for embryonic development, organogenesis and homeostasis [15]. Uncontrolled regulation of cell migration induces tumor formation and metastasis $[16,17]$. Tumor cell migration is mainly stimulated by various growth factors, such as insulin-like growth factor-1 (IGF-1), epithermal growth factor (EGF), hepatocyte growth factor (HGF), and basic fibroblast growth factor (bFGF) [18-21]. For cell migration, mammalian cells initially form lamellipodia that protrude into the direction of movement [22,23]. The lamellipodia formation is induced by actin nucleation and extension and modulated by the actin-related protein $2 / 3$ (Arp2/3) complex, suppressor of cAMP receptor/WiskottAldrich syndrome protein (WASP) family verprolinhomologous protein (Scar/WAVE), chemokine receptor, CD44, ezrin/radixin/moesin and Rho family GTPases [22-26]. 
The cell-surface $\mathrm{gClqR}$ is also found in the lamellipodia after cellular exposure to insulin, IGF-1, EGF or fetal bovine serum (FBS) [3]. Lamellipodia formation, cell migration and receptor tyrosine kinase (RTKs including insulin receptor, IGFR and EGFR) signaling is prevented by gC1qR knockdown, indicating that $\mathrm{gClqR}$ is an essential component of lamellipodia formation [3]. Because $\mathrm{gClqR}$ knockdown decreases both mitochondrial and cell-surface $\mathrm{gC} 1 \mathrm{qR}$, it is difficult to conclude that only cell-surface $\mathrm{gClqR}$ is necessary for lamellipodia formation. To overcome this weakness and elucidate the functions of the cell-surface $\mathrm{gClqR}$, we treated various cancer cells with a monoclonal mouse anti-gC1qR antibody, which was first screened by monitoring cell migration inhibition. In this study, we examined the effect of the antibody neutralization of cell-surface $\mathrm{gClqR}$ in growth factor-stimulated cell migration, lamellipodia formation, proliferation, RTK activation, angiogenesis and in vivo tumorigenesis.

\section{RESULTS}

\section{Antibody neutralization of cell-surface gC1qR prevents cell migration}

Because cell-surface gC1qR is known to increase during cancer progression and regulates lamellipodia formation and cell migration [3, 5, 12], antibody neutralization of cell-surface gC1qR might be an effective strategy for treating cancer. To identify cell-surface gC1qR-neutralizing antibodies, we screened anti-gC1qR mouse antibodies using trans-well migration assays. Fetal bovine serum (FBS)-induced A549 cell migration was monitored in trans-wells after incubation with anti-gClqR antibody obtained from different parental hybridoma cells. As shown in Figure $1 \mathrm{~A}$ and $1 \mathrm{~B}$, anti-gC1qR antibody from parental hybridoma cell line number 27 (P27) was identified as the most effective in cell migration inhibition. The P27 anti-gC1qR antibody also prevented FBS-induced cell migration in wound-healing assays (Figure $1 \mathrm{C}$ and 1D). The relative migration was reduced up to $\sim 90 \%$ in trans-well migration assays and $\sim 50 \%$ in wound-healing assays by $\mathrm{P} 27$ anti-gC1qR antibody compared to mock IgG (Figure 1B and 1D). Next, the P27 cells were further cloned a second time using semi-solid cloning to obtain optimal monoclonal mouse anti-gC1qR antibodies (mAb) for cell migration inhibition. FBS-induced A549 cell migration was monitored in wound healing assay after preincubating the cells with mock IgG or monoclonal mouse anti-gC1qR antibodies obtained from each clone. Because mAb 3D9 was the most effective antibody at preventing FBS-stimulated cell migration of A549 cells (Figure 1E), we used the mAb 3D9 to neutralize cell-surface gC1qR in further experiments.

Next, we tested whether mAb 3D9 inhibits FBSinduced cell migration in various cancer cell lines, such as human breast carcinoma MDA-MB-231, human breast carcinoma MCF7, human cervix carcinoma HeLa and human lung carcinoma A549 cells, which expressed gC1qR in the plasma membrane and mitochondria (Supplementary Figure 1A). In the wound healing assay, mAb 3D9 inhibited FBS-induced cell migration of HeLa, MCF7, A549 and MDA-MB-231 cells (Figure 2A and 2B). Notably, the FBS-induced cell migration was dramatically reduced by mAb 3D9 in A549 and MDA-MB-231 cells, which highly expressed $\mathrm{gC} 1 \mathrm{qR}$ in the plasma membrane (Supplementary Figure 1A). Thus, A549 and MDA-MB-231 cell lines were selected for further investigating the effect of mAb 3D9 on cell migration inhibition.

We examined EGF- and IGF-1-induced cell migration of A549 and MDA-MB-231 cells in the presence of $\mathrm{mAb} 3 \mathrm{D} 9$. In wound-healing assays of both cells, EGF- and IGF-1-induced cell migration was significantly inhibited by mAb 3D9 (Figure 2C and 2D and Supplementary Figure $1 \mathrm{~B}$ and $1 \mathrm{C}$ ). We also confirmed that mAb 3D9 inhibited FBS-, EGF- and IGF-1-induced cell migration in trans-well migration assays of both cells (Figure 2E and 2F and Supplementary Figure 1D and $1 \mathrm{E})$. These results suggest that $\mathrm{mAb} 3 \mathrm{D} 9$ is useful for neutralizing the cell-surface $\mathrm{gClqR}$ in various cancer cells.

\section{Antibody neutralization of cell-surface gC1qR prevents lamellipodia formation}

It is known that cell-surface $\mathrm{gCl} 1 \mathrm{qR}$ is a key regulator for lamellipodia formation in A549 cells [3]. To assess the involvement of cell-surface $\mathrm{gClqR}$ in lamellipodia formation, we investigated the $\mathrm{gClqR}$ and $\mathrm{CD} 44$ localization of lamellipodia in various non-permeabilized cancer cells using mAb 3D9. CD44 was used as a cellsurface marker of lamellipodia. As shown in Figure 3A, cellsurface $\mathrm{gClqR}$ and CD44 were dispersed on the cell-surface of serum-starved and mock IgG-treated A549, MDAMB-231, MCF7 and HeLa cells. After FBS stimulation in the presence of mock $\mathrm{IgG}$, the cell-surface $\mathrm{gClqR}$ and CD44 appeared in the lamellipodia in all tested cell lines. In the presence of $\mathrm{mAb} 3 \mathrm{D} 9$, the $\mathrm{gClqR}$ and CD44-containing lamellipodia disappeared even with FBS stimulation, indicating that $\mathrm{mAb} 3 \mathrm{D} 9$ prevents FBS-stimulated lamellipodia formation in various cell lines (Figure 3A). The $\mathrm{mAb}$ 3D9 had the strongest inhibitory effect on lamellipodia formation in A549 and MDA-MB-231 cells (Figure 3B). In addition, EGF- and IGF-1-stimulated lamellipodia formation in A549 cells was prevented by mAb 3D9 (Figure $3 \mathrm{C}$ and 3D). These data suggest that mAb 3D9 prevents FBS-, EGF- or IGF-1-stimulated lamellipodia formation by neutralizing cell-surface gClqR.

\section{Antibody neutralization of cell-surface gC1qR prevents the activation of RTKs}

Next, we tested whether mAb 3D9 affects the FBS, EGF and IGF-1 signal transduction pathways. In the 


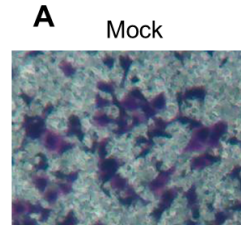

6P

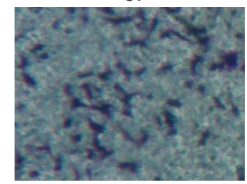

$16 \mathrm{P}$

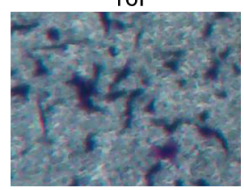

21P

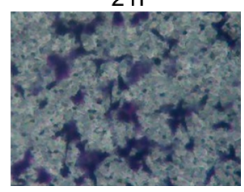

$2 \mathrm{P}$

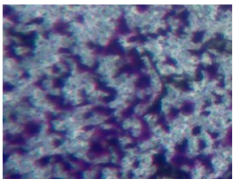

$7 P$

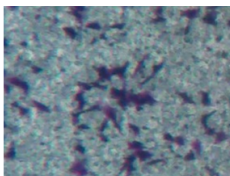

17P

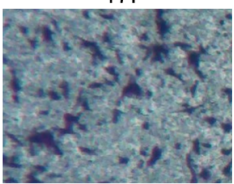

$26 \mathrm{P}$

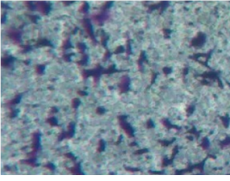

$3 P$

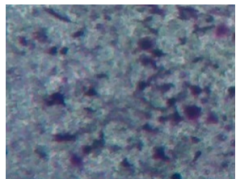

$11 \mathrm{P}$

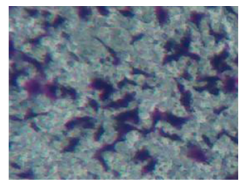

18P

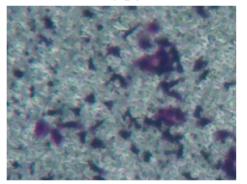

27P

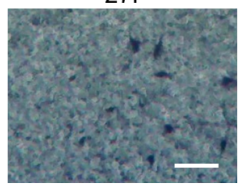

4P

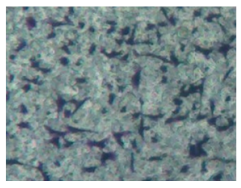

$12 \mathrm{P}$

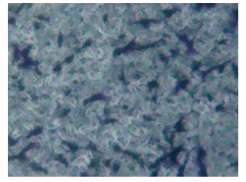

$19 P$

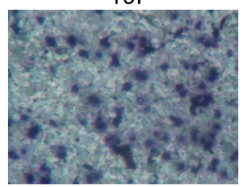

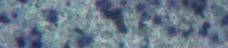

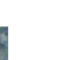 \\ .}
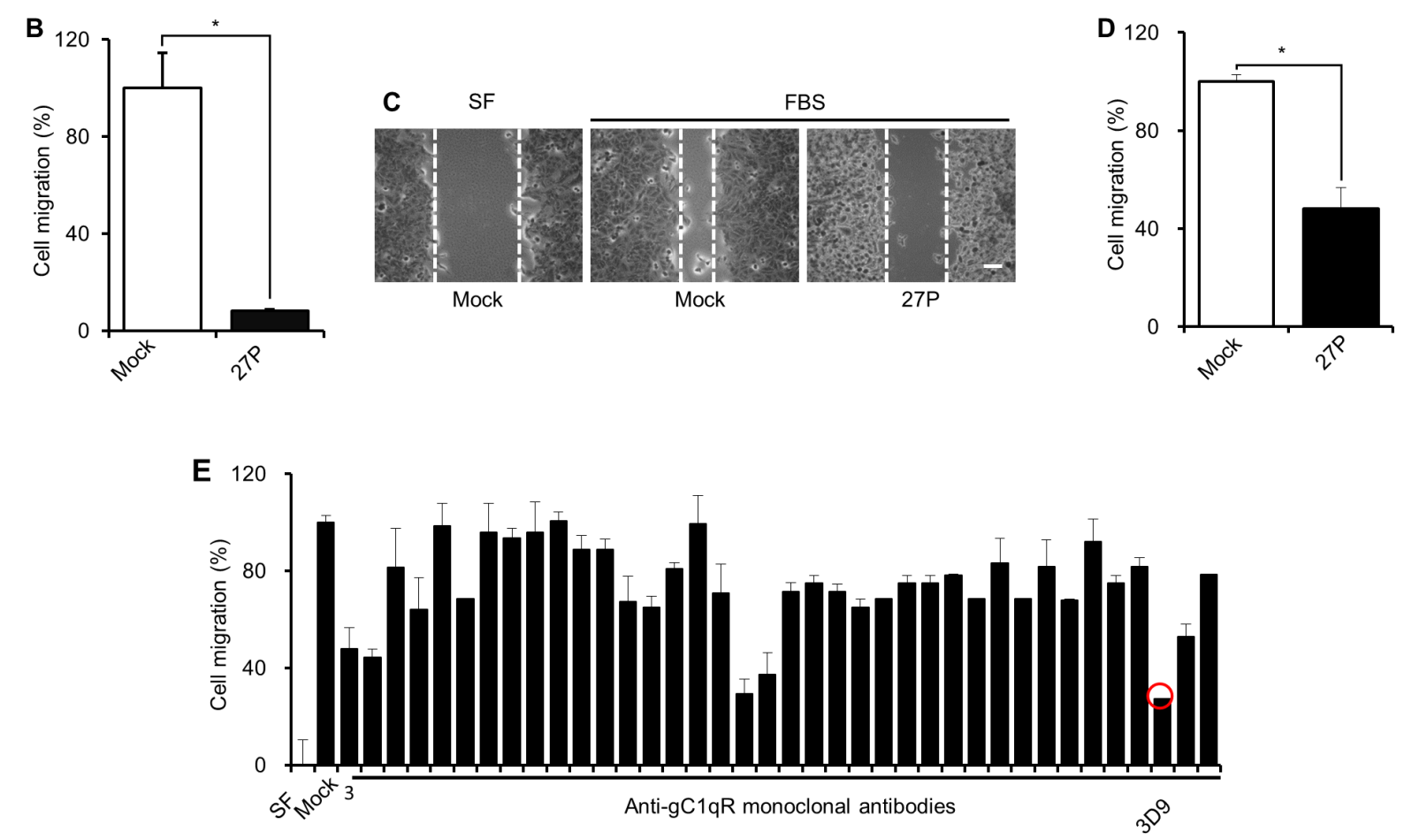

Figure 1: Preparation of a gC1qR-neutralizing antibody. A and B. Different anti-gC1qR antibodies were purified from the cell culture fluid obtained from different hybridoma parental cells. A549 cells were serum-starved for $18 \mathrm{~h}$, pretreated with mock IgG and anti-gClqR antibodies for $4 \mathrm{~h}$ and trypsinized. The A549 cells ( $4 \times 10^{4}$ cells) were loaded into the upper chamber in trans-well plate in the presence of mock IgG or anti-gClqR antibodies $(10 \mu \mathrm{g} / \mathrm{mL})$ and stimulated for $18 \mathrm{~h}$ by $10 \% \mathrm{FBS}$. The trans-well membrane was stained by crystal violet (A). Cell migration was statistically determined in the presence of $\mathrm{P} 27$ anti-gC1qR antibody ( $\mathrm{n}=3)(\mathrm{B})$. C and D. Cell migration of A549 was determined by wound healing assays. A549 cells were serum-starved for $18 \mathrm{~h}$ and pretreated with $10 \mu \mathrm{g} / \mathrm{mL} \mathrm{mock}$ IgG or P27 anti-gC1qR antibody for $4 \mathrm{~h}$. The cells were scraped and stimulated by $10 \% \mathrm{FBS}$ for $30 \mathrm{~h}$. Cells migrating into a wounded area were observed after staining with crystal violet (C). Cell migration was statistically determined (n=3) (D). E. P27 parental cells were further sub-cloned by semi-solid cloning. Anti-gC1qR monoclonal mouse antibodies were prepared from the cell culture media from each sub-clone. Cell migration of A549 cells was statistically determined by wound healing assay in the presence of mock IgG or anti-gC1qR antibody $(10 \mu \mathrm{g} / \mathrm{mL})(\mathrm{n}=3)$. Scale bar $=100 \mu \mathrm{m}$. Graphs represent mean \pm standard error of the mean (s.e.m.) ${ }^{*} p<0.01$, student $t$ test. 
presence of mock $\mathrm{IgG}$ or mAb 3D9, the phosphorylation of the RTKs, Akt and Erk was monitored in FBS-, EGFand IGF-1-stimulated A549 and MDA-MB-231 cells. In contrast to mock IgG-pretreated cells, IGFR, EGFR, Akt and Erk phosphorylation was significantly reduced in mAb 3D9-pretreated A549 (Figure 4A-4C and Figure
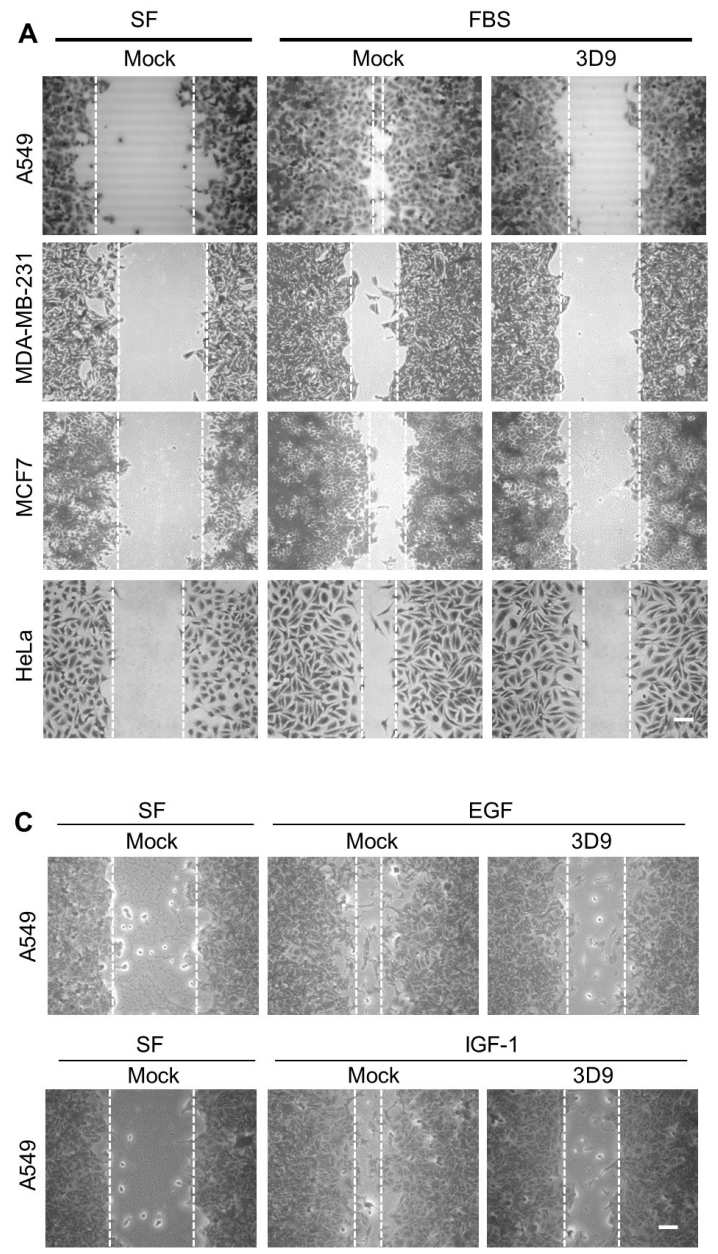

IGF-1

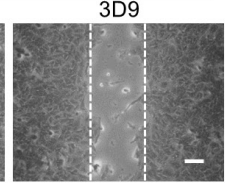

4E-4G) and MDA-MB-231 cells (Figure 4H-4J and Figure $4 \mathrm{~K}-4 \mathrm{M})$. We also monitored PDGF signaling in mock IgG- or mAb 3D9-treated A549 cells. As shown in Figure 4D and Figure 4E-4G, there was no difference in the phosphorylation of PDGFR, Akt and Erk between mock IgG- and mAb 3D9-treated A549 cells. These data suggest
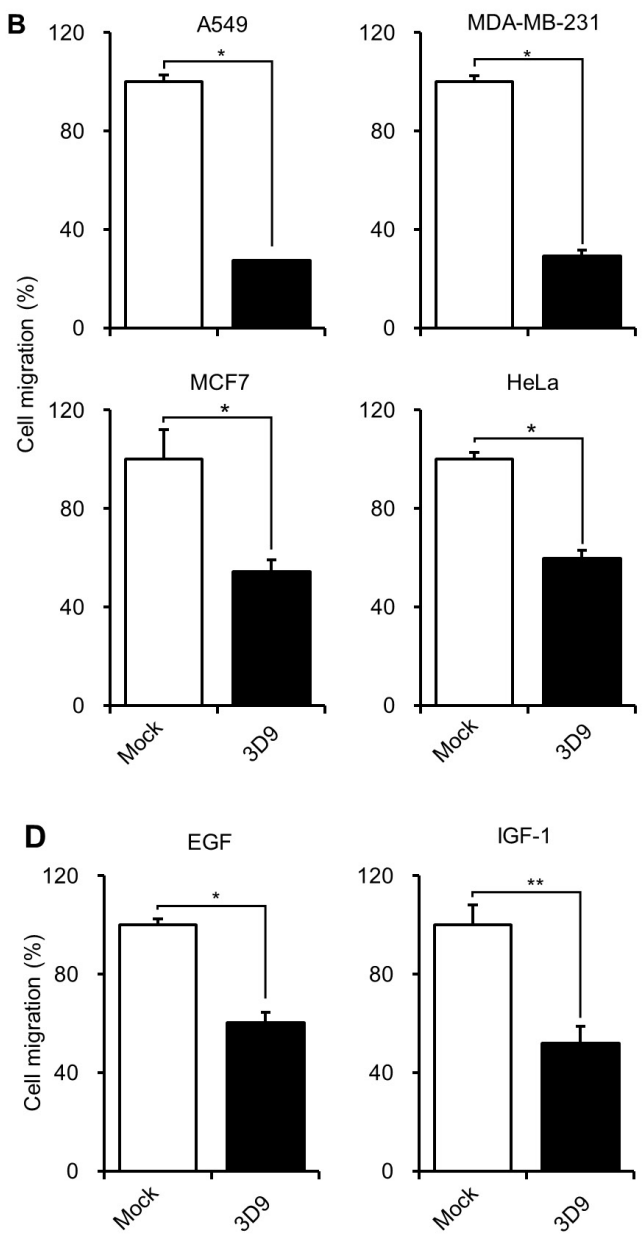

$\mathbf{F}$
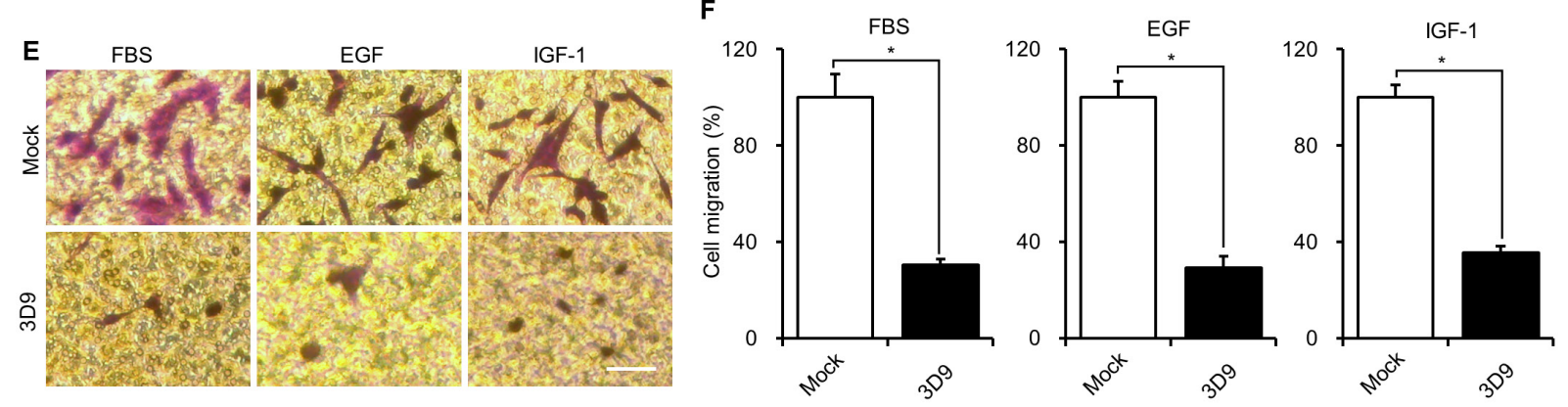

Figure 2: Antibody neutralization of gC1qR prevents cell migration. A and B. A549, MDA-MB-231, MCF7 and HeLa cells were serum-starved for $18 \mathrm{~h}$ and pretreated with $10 \mu \mathrm{g} / \mathrm{mL}$ of mock IgG or anti-gC1qR antibody (mAb 3D9) for $4 \mathrm{~h}$. FBS-induced cell migration was determined by wound-healing assays after stimulating cells with FBS (10\%) for $30 \mathrm{~h}$ with A549, MCF7 and MDA-MB-231 cells and for $12 \mathrm{~h}$ with HeLa cells (A). Cell migration was statistically determined ( $\mathrm{n}=3$ ) (B). C and D. EGF- and IGF-1-induced cell migration was determined by wound-healing assay. A549 cells were serum-starved for $18 \mathrm{~h}$, pretreated with $10 \mu \mathrm{g} / \mathrm{mL}$ of mock IgG or mAb 3D9 for $4 \mathrm{~h}$ and stimulated with EGF $(50 \mathrm{ng} / \mathrm{mL})$ or IGF-1 $(100 \mathrm{ng} / \mathrm{mL})$ for $30 \mathrm{~h}(\mathrm{C})$. Cell migration was statistically determined (n=3) (D). E and F. FBS-, EGF- and IGF-1-induced cell migration of A549 cells was determined by trans-well assay in the presence of mock IgG or mAb 3D9 (E). Cell migration was statistically determined $(\mathrm{n}=3)(\mathrm{F})$. Scale bar $=100 \mu \mathrm{m}$. Graphs represent mean \pm s.e.m. $* p<0.01$, student $t$ test. 

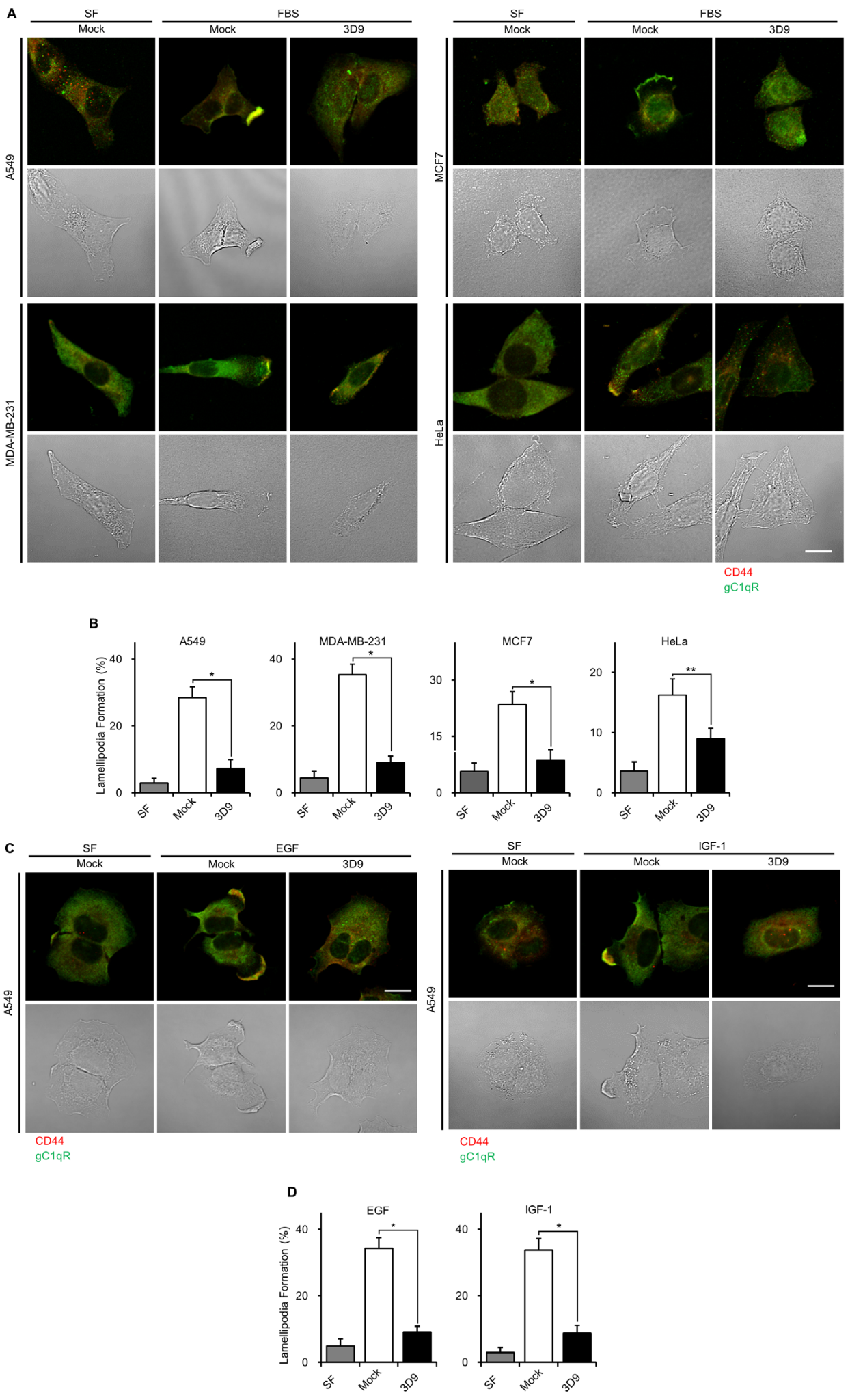

Figure 3: Antibody neutralization of gC1qR prevents lamellipodia formation. A and B. MDA-MB231, A549, MCF7 and HeLa cells were grown to non-confluency, serum-starved for $18 \mathrm{~h}$, pretreated with $10 \mu \mathrm{g} / \mathrm{mL}$ of mock IgG or mAb 3D9 for $4 \mathrm{~h}$ and stimulated for $10 \mathrm{~min}$ by $10 \% \mathrm{FBS}$. Cellular localization of $\mathrm{gClqR}$ and $\mathrm{CD} 44$ was determined by non-permeabilized immunofluorescence (A). Lamellipodia-containing cells (\%) were statistically determined from 12 different imaging fields (B). C and D. A549 cells were grown to non-confluency, serum-starved for $18 \mathrm{~h}$, pretreated with $10 \mu \mathrm{g} / \mathrm{mL}$ of mock IgG or mAb 3D9 for $4 \mathrm{~h}$ and stimulated for $10 \mathrm{~min}$ by EGF $(50 \mathrm{ng} / \mathrm{mL})$ and IGF-1 $(100 \mathrm{ng} / \mathrm{mL})$ for $10 \mathrm{~min}$. Cellular localization of $\mathrm{gClqR}$ and CD44 was determined by non-permeabilized immunofluorescence (C). Lamellipodia-containing cells (\%) were statistically determined from 12 different imaging fields (D). Scale bar $=$ $10 \mu \mathrm{m}$. Graphs represent mean \pm s.e.m. ${ }^{*} p<0.01$ and ${ }^{* *} p<0.05$, student $t$ test. 

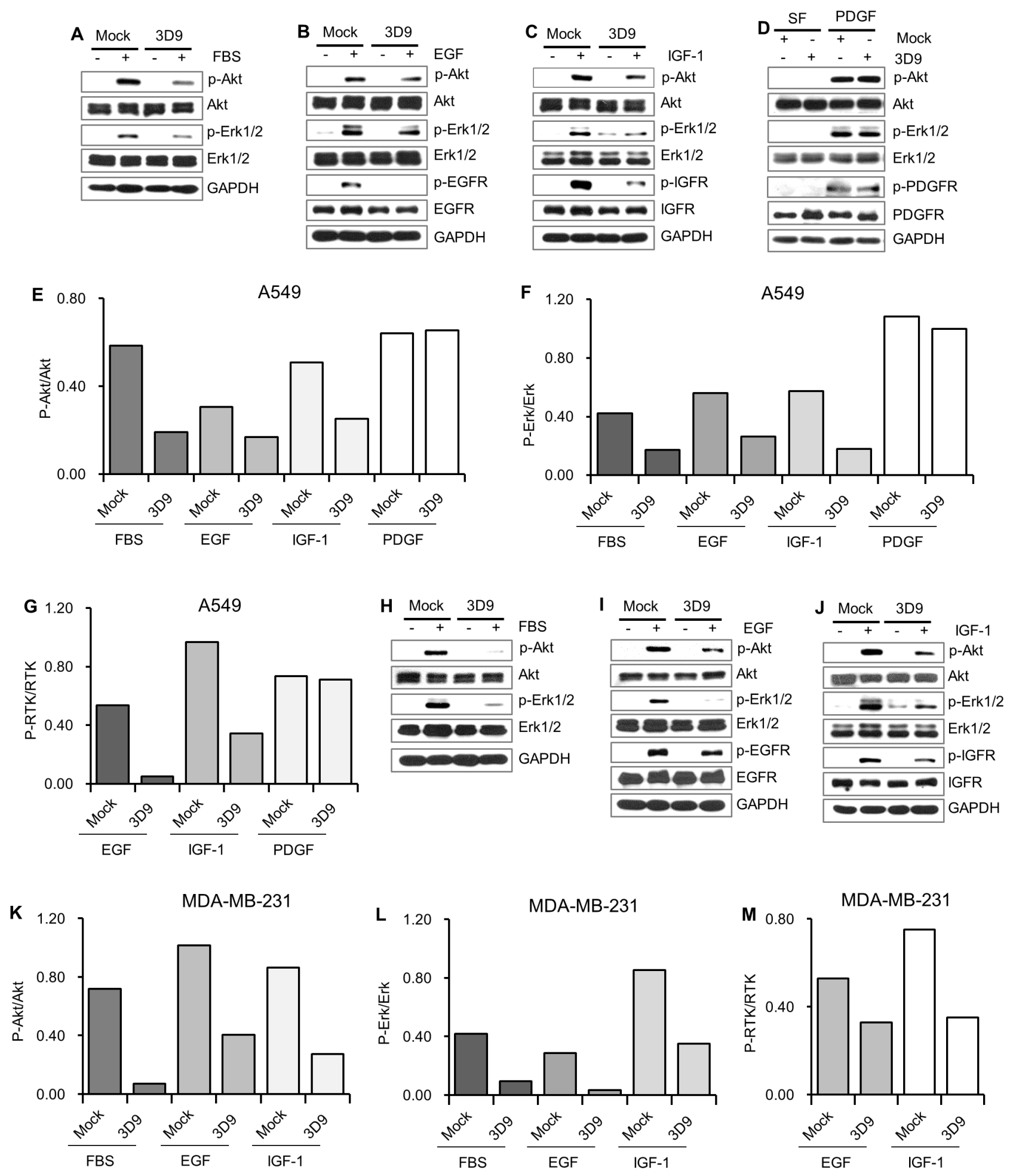

Figure 4: Antibody neutralization of gC1qR prevents receptor tyrosine kinases (RTKs) signaling. A-D. A549 cells were serum-starved for $18 \mathrm{~h}$ and pretreated with $10 \mu \mathrm{g} / \mathrm{mL}$ of mock IgG or mAb 3D9 for $4 \mathrm{~h}$ and stimulated for $10 \mathrm{~min}$ by FBS (10\%) (A), EGF (50 ng/mL) (B), IGF-1 (100 ng/mL) (C) and PDGF (20 ng/mL) (D) for 10 min. H-J. MDA-MB-231 cells were serum-starved for 18 $\mathrm{h}$ and pretreated with $10 \mu \mathrm{g} / \mathrm{mL}$ of mock IgG or mAb 3D9 for $4 \mathrm{~h}$ and stimulated for $10 \mathrm{~min}$ by FBS $(10 \%)(\mathrm{H}), \mathrm{EGF}(50 \mathrm{ng} / \mathrm{mL})(\mathrm{I})$ and IGF-1 (100 ng/mL) (J). Phosphorylated and total forms of Akt, Erk1/2, EGFR, IGFR and PDGFR were analyzed by immunoblotting using GAPDH as a loading control. The ratio of p-Akt/Akt $\mathbf{E}$ and K., p-Erk/Erk F and L., p-EGFR/EGFR G and M., p-IGFR/IGFR (G and M) and p-PDGFR/PDGFR (G) was calculated from the band intensities for p-Akt, Akt, p-Erk1/2, Erk1/2, p-EGFR, EGFR, p-IGFR, IGFR, p-PDGFR and PDGFR in the immunoblottings (A-D and H-J). 
that cell-surface $\mathrm{gClqR}$ neutralization with mAb 3D9 prevents the activation of IGFR and EGFR but not PDGFR.

\section{Antibody neutralization of cell-surface gC1qR prevents the activation of focal adhesion kinase}

Because cell-surface $\mathrm{gClqR}$ binds to various extracellular matrix components [3, 8-10, 27], antibody neutralization of cell-surface gC1qR might affect cell adhesion and spreading. We observed the cellular morphology of A549 after cell plating in the presence of mock IgG or mAb 3D9. Cell spreading was delayed in the presence of mAb 3D9 at $6 \mathrm{~h}$ after cell plating (Figure $5 \mathrm{~A}$, two upper panels). Interestingly, mock IgG-treated cells showed a dispersed growth pattern whereas $\mathrm{mAb}$ 3D9-treated cells had an aggregated growth pattern at 48 $\mathrm{h}$ after cell plating (Figure 5A, two lower panels). In the presence of $\mathrm{mAb} 3 \mathrm{D} 9$, the activation of focal adhesion kinase (FAK) was determined by immunoblotting and immunofluorescence. As shown in Figure 5B-5F, mAb 3D9 dramatically reduced FAK phosphorylation at Y397 and Y925 in FBS-, EGF-, and IGF-1-stimulated A549 cells but not in PDGF-stimulated cells. On the basis of these data, we conclude that the antibody neutralization of cell-surface $\mathrm{gClqR}$ prevents FAK activation stimulated with FBS-, EGF-, and IGF-1 but not PDGF.

\section{Antibody neutralization of cell-surface gC1qR prevents angiogenesis in HUVEC}

Because $\mathrm{gClqR}$ is expressed on the cell-surface in endothelial cells $[5,7,28]$, it is tempting to speculate that the antibody neutralization of cell-surface $\mathrm{gClqR}$ might inhibit angiogenesis in endothelial cells. To address the issue, we investigated the effect of mAb 3D9 on lamellipodia formation, cell migration, tube formation and vascular endothelial growth factor (VEGF) signaling in human umbilical vein endothelial cells (HUVEC). The lamellipodial localization of cell-surface $\mathrm{gClqR}$ and CD44 were observed in the HUVEC stimulated by EGM-2 containing endothelial growth factors or VEGF in the presence of mock $\operatorname{IgG}$ but not in the presence of $\mathrm{mAb} 3 \mathrm{D} 9$ (Figure 6A and 6B). The neutralization of cell-surface gC1qR with mAb 3D9 significantly reduced EGM-2-stimulated HUVEC migration and tube formation as determined by trans-well migration and tube formation assays, respectively (Figure 6C and 6D). The mAb 3D9 also decreased EGM-2- or VEGF-stimulated phosphorylation of VEGFR, Akt and Erk (Figure 6E and 6F). Based on the data in HUVEC, we conclude that mAb 3D9 could be used as an anti-angiogenic drug for cancer treatment.

\section{Antibody neutralization of cell-surface gC1qR prevents in vivo tumorigenesis}

We investigated whether antibody neutralization of cell-surface gClqR inhibits growth factors-induced cellular proliferation. As shown in Figure 7A, mAb 3D9 decreased FBS-, EGF-, or IGF-1-stimulated cellular proliferation of A549 cells. To explore the possibility that mAb 3D9 could be used as an anti-cancer drug, we next examined whether mAb 3D9 could affect in vivo tumor growth after A549 cells were subcutaneously injected into BALB/c athymic mice. Tumor size was measured for 32 days after A549 tumorbearing mice were treated twice a week with PBS or $\mathrm{mAb}$ 3D9. The administration of mAb 3D9 delayed tumor growth (Figure 7B). mAb 3D9-treated mice showed reduced tumor weights and volumes after 32 days, compared to PBStreated mice (Figure 7C-7F). These results suggest that the $\mathrm{mAb} 3 \mathrm{D} 9$ could be used as an anti-cancer drug.

\section{DISCUSSION}

Although $\mathrm{gClqR}$ is first identified as a receptor of the globular head for complement subunit $\mathrm{C} 1 \mathrm{q}$ and as a splicing factor-associated protein, the $\mathrm{gClqR}$ is mainly localized in the mitochondria and maintains mitochondrial structure and function $[1,2,29]$. The systemic disruption of $\mathrm{gClqR}$ reduces the expression level of mitochondrial oxidative phosphorylation (OXPHOS) subunits, leading to mitochondrial dysfunction with reduced mitochondrial respiration $[29,30]$. These findings suggest that $\mathrm{gClqR}$ is a major mitochondrial protein, which is necessary for mitochondrial integrity and function. In spite of its mitochondrial localization, $\mathrm{gCl} 1 \mathrm{qR}$ has been identified on the cell-surface of various mammalian cells [2-7]. Because $\mathrm{gClqR}$ interacts with plasma proteins, extracellular matrix molecules and different pathogens [2, 6, 8-10, 31, 32], $\mathrm{gClqR}$ is suggested to localize in the cell-surface or extracellular space. Indeed, $\mathrm{gClqR}$ is found on the cellsurface of non-permeabilized 3T3-L1 adipocytes and various cancer cells, including A549, MDA-MB435 and MDA-MB231 cells as determined by immunofluorescence or FACS analysis [3-5]. Fluorescently labeled Lyp1 interacts with $\mathrm{gClqR}$ on the cell-surface after its intravenous administration in mice [33]. Interestingly, recombinant $\mathrm{gClqR}$ is also found on the cell-surface, leading to cell migration via interaction with $\alpha v \beta 3$ integrin in B16F10 cells [34]. In addition, cell survival and tumorigenicity are enhanced via the molecular interaction between $\mathrm{gClqR}$ and hyaluronic acid (HA) in gC1qRoverexpressing HepG2 cells [35]. These data indicate that $\mathrm{gClqR}$ is a genuine cell-surface protein.

The cell-surface $\mathrm{gClqR}$ plays an important role in lamellipodia formation because it is found in growth factorinduced lamellipodia and $\mathrm{gClqR}$ knockdown prevents lamellipodia formation, cell migration, cell attachment and RTK activation in A549 cells [3]. Our present data also show that antibody neutralization of cell-surface $\mathrm{gClqR}$ prevented ligand-induced lamellipodia formation, cell migration, cell attachment and RTK signaling in various cell lines such as A549, MDA-MB-231, MCF7, HeLa and HUVEC, suggesting that antibody neutralization of 
cell-surface gC1qR can be a useful treatment strategy for various cancers that overexpress $\mathrm{gClqR}$ and $\mathrm{RTKs}$ in the plasma membrane. Indeed, mAb 3D9 reduced tumor growth in A549 tumor-bearing nude mice.
It is tempting to speculate that integrin might be a mediator for $\mathrm{gC1} 1 \mathrm{qR}$-induced RTK activation, lamellipodia formation and cell migration because of an integrin-RTK crosstalk $[36,37]$ and the molecular interaction of integrin
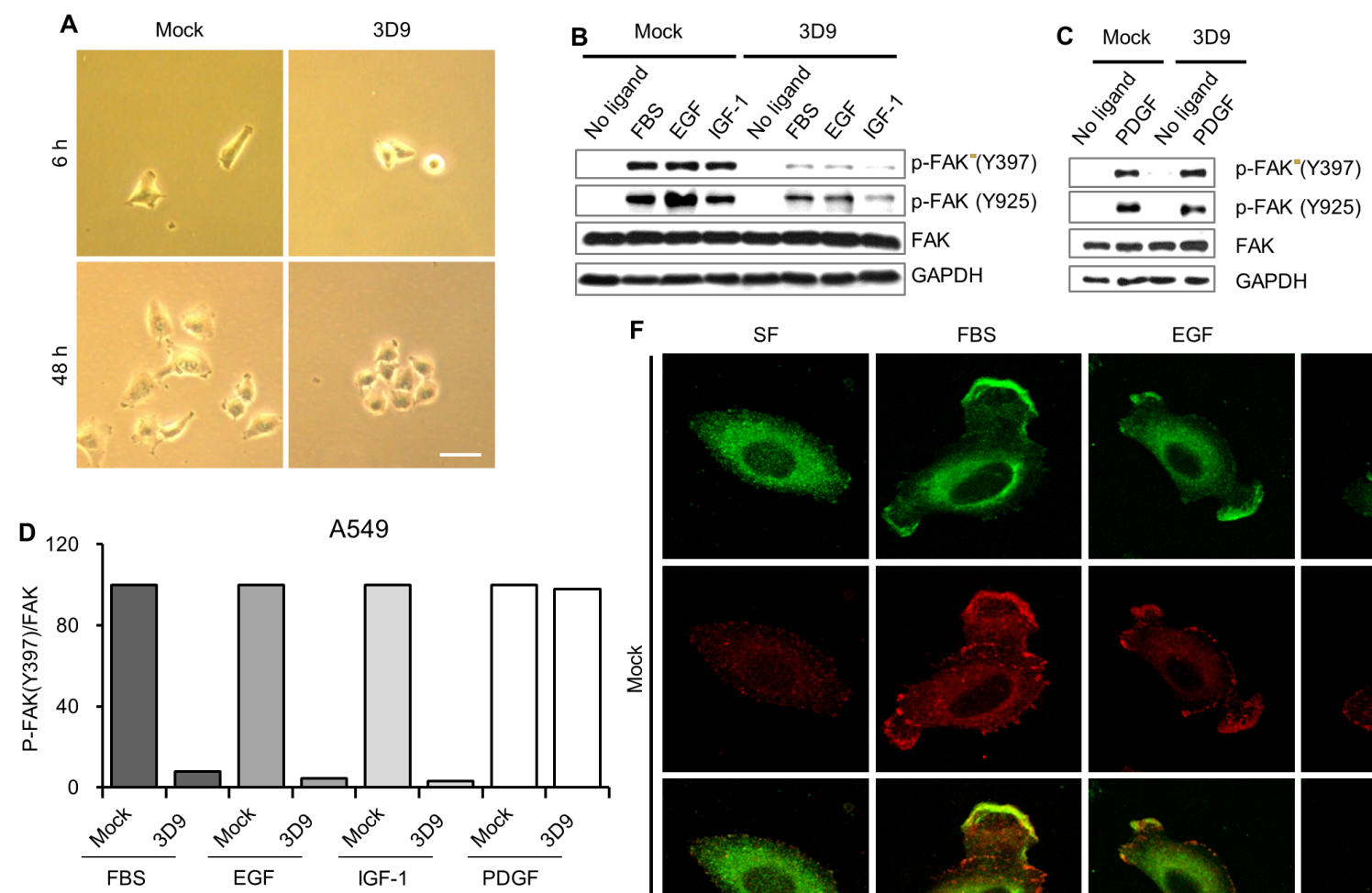

$\mathbf{F}$

SF

FBS

EGF

IGF-1
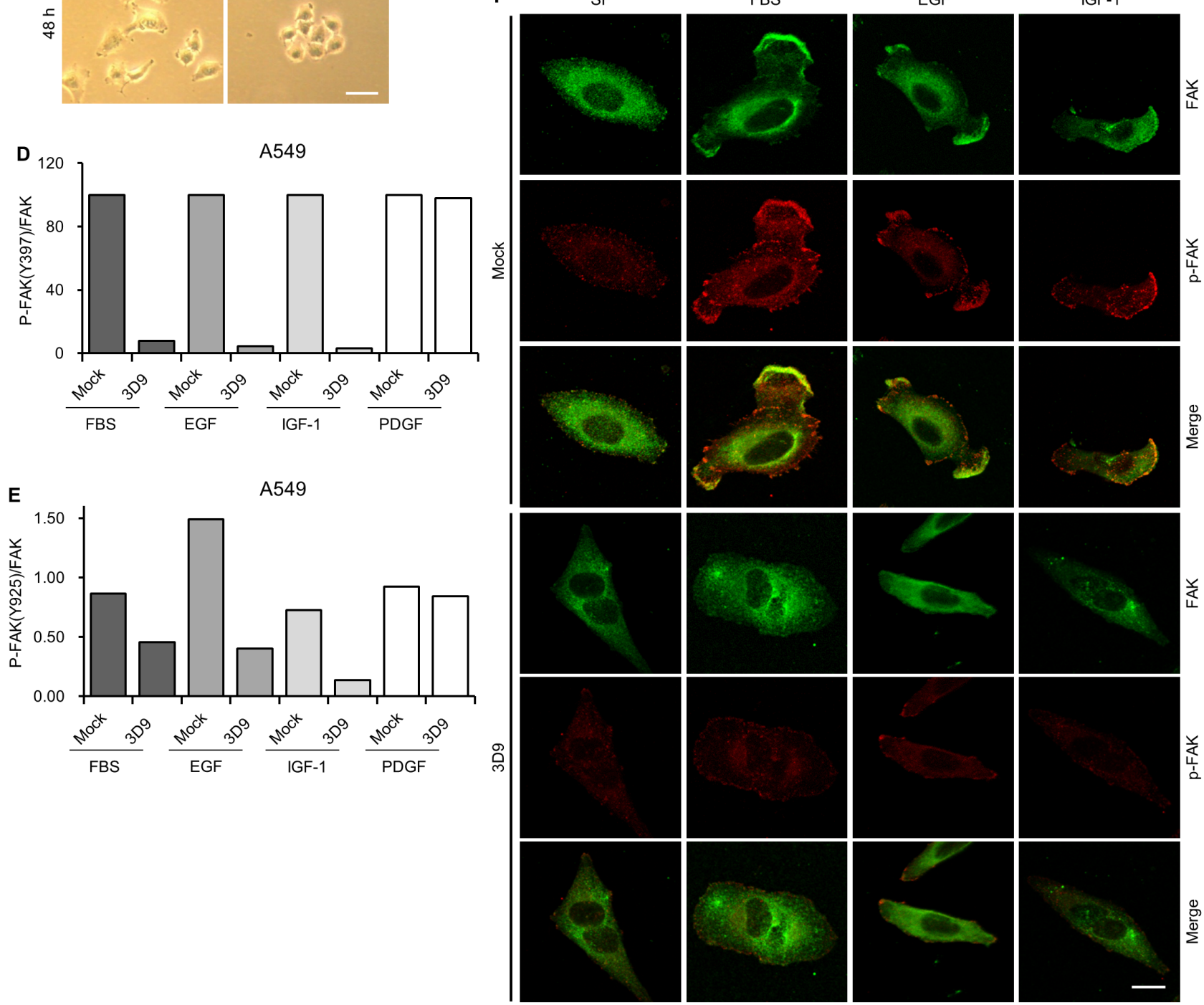

p-FAK(Y397)

FAK

Figure 5: Antibody neutralization of gC1qR prevents the activation of focal adhesion kinase (FAK). A. A549 cells were grown after plating in the presence of $10 \mu \mathrm{g} / \mathrm{mL}$ of mock IgG or mAb 3D9. Cellular morphology was observed with a light microscopy $6 \mathrm{~h}$ and $48 \mathrm{~h}$ after cell plating. Scale bar $=50 \mu \mathrm{m}$. B and C. A549 was serum-starved for $18 \mathrm{~h}$ and pretreated with $10 \mu \mathrm{g} / \mathrm{mL}$ of mock IgG or mAb 3D9 for $4 \mathrm{~h}$ and stimulated for $10 \mathrm{~min}$ by FBS (10\%), EGF (50 ng/mL), IGF-1 (100 ng/mL) and PDGF (20ng/mL) for $10 \mathrm{~min}$. Phosphorylated (at Y397 or Y925) and total forms of FAK were analyzed by immunoblotting using GAPDH as a loading control (B and C). The ratio of p-FAK/FAK D and E. was calculated from the band intensities for p-FAK (Y397), p-FAK (Y925) and FAK in the immunoblottings (B and C). Cellular localization of p-FAK (Y397) and FAK was determined by immunofluorescence $\mathbf{F}$. Scale bar $=10 \mu \mathrm{m}$. 
A
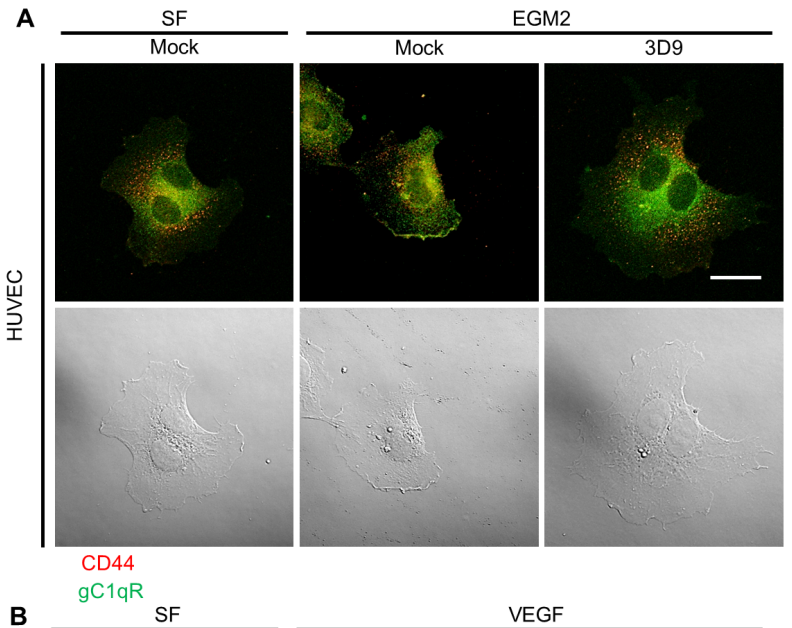

(1)

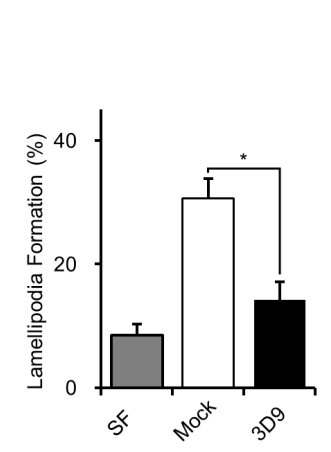

B
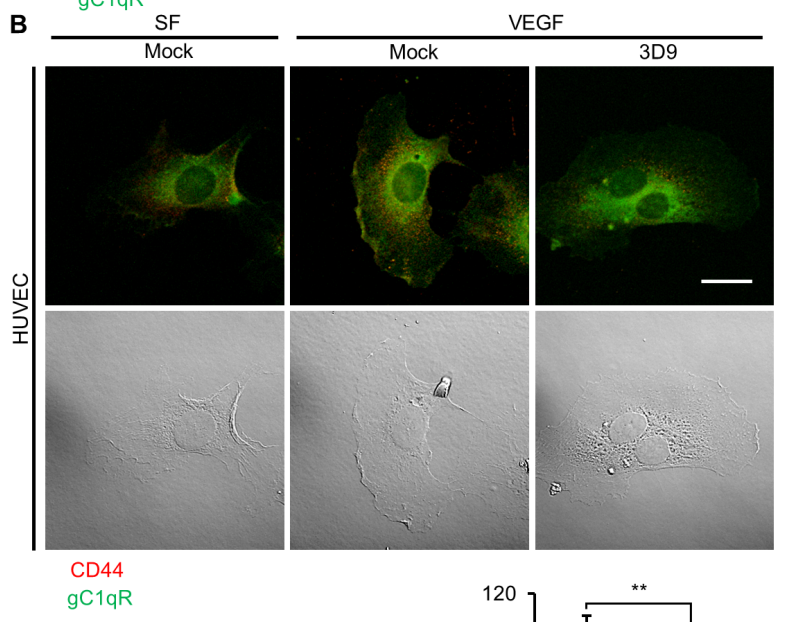

C
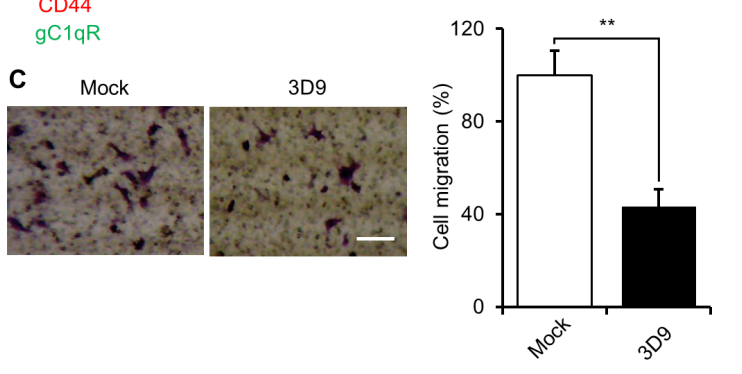

E
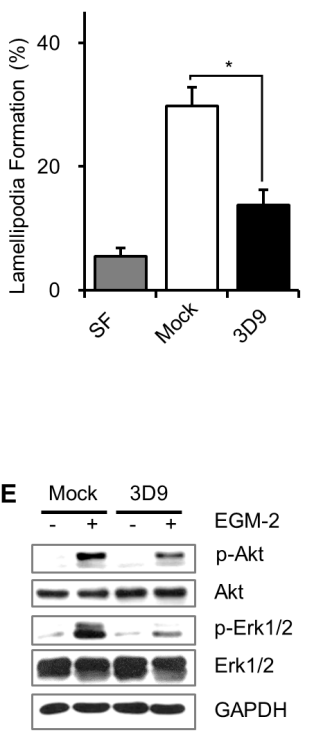

D

3D9
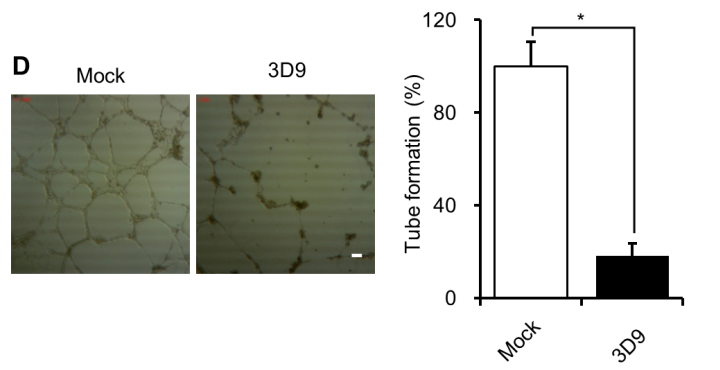

Figure 6: Antibody neutralization of gC1qR prevents lamellipodia formation, cell migration and VEGF signaling in HUVEC. A and B. Human umbilical vein endothelial cells (HUVEC) were grown to non-confluency, serum-starved with $0.2 \%$ FBS-containing endothelial basal media (EBM-2) for $18 \mathrm{~h}$, pretreated with $10 \mu \mathrm{g} / \mathrm{mL}$ of mock $\mathrm{IgG}$ or mAb 3D9 for $4 \mathrm{~h}$ and stimulated with endothelial growth media (EGM-2) (A) or vascular endothelial growth factor (VEGF, $50 \mathrm{ng} / \mathrm{mL}$ ) (B) for $10 \mathrm{~min}$. Cellular localization of gC1qR and CD44 was determined by non-permeabilized immunofluorescence (right panels). Lamellipodia-containing cells (\%) were statistically determined from 12 different imaging fields (left panels). Bar $=20 \mu \mathrm{m}$. C. EGM-2-induced cell migration of HUVEC was determined by trans-well assay in the presence of $10 \mu \mathrm{g} / \mathrm{mL}$ of mock IgG or mAb 3D9. The trans-well membrane was stained by crystal violet (left panel). Cell migration was statistically determined from three independent experiments (right panel). Bar $=50 \mu \mathrm{m}$. D. Serum-starved HUVEC were serum-starved in $0.2 \%$ FBS-containing EBM-2 for $18 \mathrm{~h}$ and trypsinized. The cells were loaded into a Matrigel-coated cell plate and tube formation was induced with EGM-2 for $18 \mathrm{~h}$ in the presence of $200 \mu \mathrm{g} / \mathrm{mL}$ mock IgG or mAb 3D9. Scale bar $=100 \mu \mathrm{m}$. E and F. Serum-starved HUVEC were pretreated with $10 \mu \mathrm{g} / \mathrm{mL}$ of mock IgG or mAb 3D9 for $4 \mathrm{~h}$ and stimulated by EGM-2 (E) or VEGF (50 ng/mL) (F) for $10 \mathrm{~min}$. Phosphorylated and total forms of Akt, Erk1/2 and VEGFR were analyzed by immunoblotting using GAPDH as a loading control. ${ }^{*} p<0.01$ and ${ }^{* *} p<0.05$, student $t$ test. 
$\alpha_{\mathrm{v}} \beta_{3}$ with exogenous gC1qR [34]. The administration of recombinant $\mathrm{gCl} 1 \mathrm{qR}$ induces cell migration via integrinand NFkB-dependent matrix metalloprotease-2 (MMP-2) activation in B16F10 mouse melanoma cells [34]. Because the recombinant $\mathrm{gClqR}$-induced cell migration was prevented in the presence of anti- $\alpha_{\mathrm{V}} \beta_{3}$ integrin antibody or $\alpha_{\mathrm{v}} \beta_{3}$-binding peptide GRGDSP, $\alpha_{\mathrm{v}} \beta_{3}$ integrin might be required for the exogenous $\mathrm{gCl} 1 \mathrm{qR}$-induced cell migration
[34]. However, in A549 cells with low expression level of $\alpha_{v} \beta_{3}$ integrin [38], antibody neutralization of surface $\mathrm{gC} 1 \mathrm{qR}$ prevented growth factors-induced lamellipodia formation and cell migration. We also failed to demonstrate the molecular interaction between endogenous $\mathrm{gC} 1 \mathrm{qR}$ and $\alpha_{\mathrm{v}} \beta_{3}$ integrin in different mammalian cells stimulated IGF or EGF. Thus, it seems that integrin $\alpha_{\mathrm{v}} \beta_{3}$ integrin may not be involved in $\mathrm{gClqR}$-mediated RTK activation,
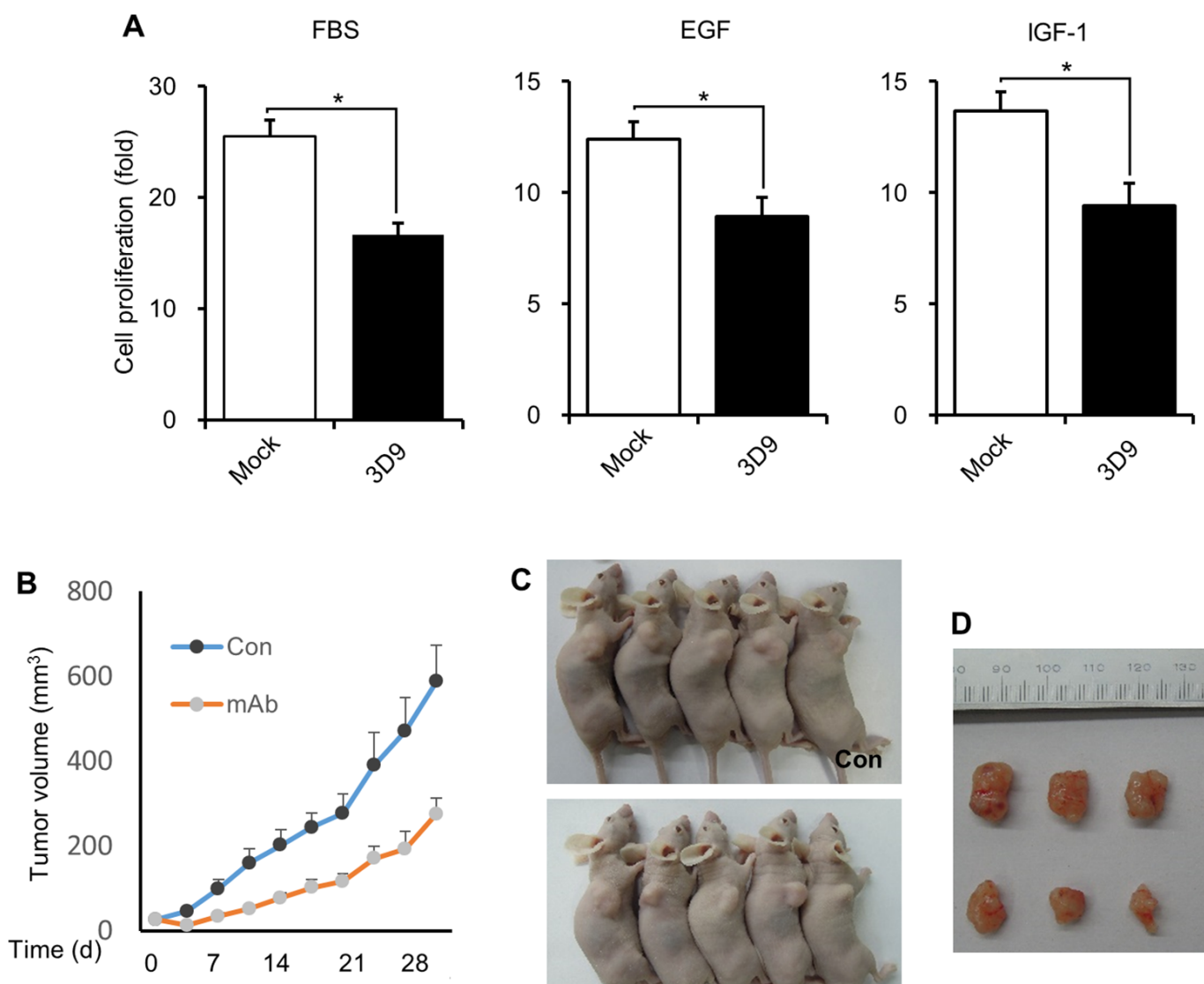

C

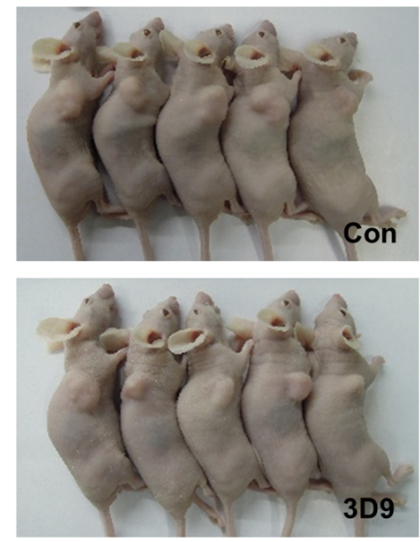

D

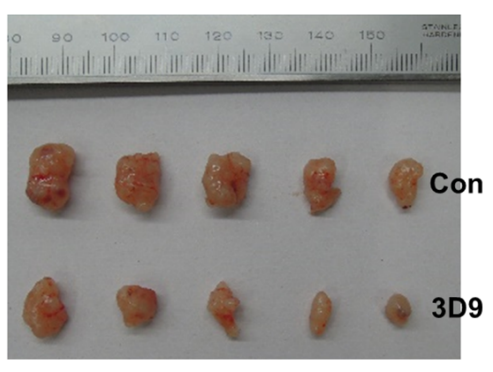

\section{E}

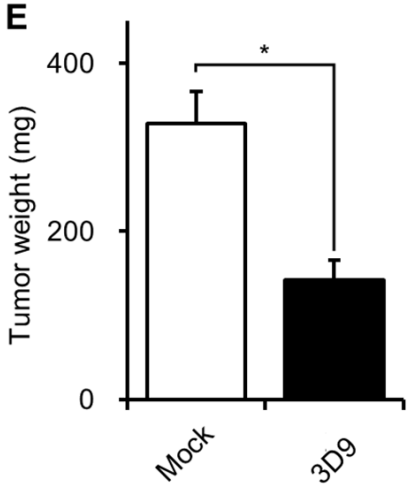

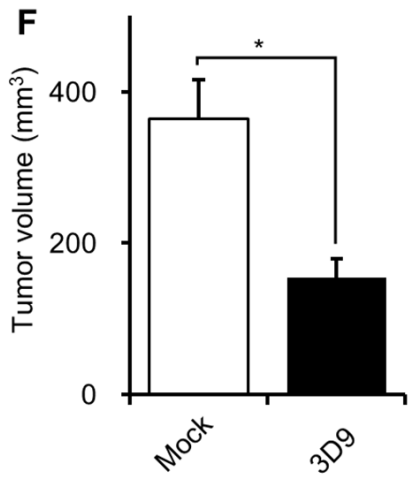

Figure 7: Antibody neutralization of $\mathbf{g C 1 q R}$ prevents in vivo tumor growth. A. A549 cells $\left(2 \times 10^{4}\right)$ were seeded into 6 -well plate in the presence $10 \mu \mathrm{g} / \mathrm{mL}$ of mock IgG or mAb 3D9 and further grown for 4 days after adding FBS (10\%), EGF (50 ng/mL) or IGF$1(100 \mathrm{ng} / \mathrm{mL})$. Cell number was counted from three independent experiments using a hemocytometer. B-D. A549 cells $\left(3 \mathrm{x} 10^{6}\right)$ were subcutaneously injected into BALB/c athymic mice $(\mathrm{n}=5) . \mathrm{mAb} 3 \mathrm{D} 9(10 \mathrm{mg} / \mathrm{kg})$ or PBS (control) was intraperitoneally injected twice a week in the tumor-bearing mice. Tumor volume was measured twice a week until day 32 (B) and photographs were taken on day 32 (C and D). ${ }^{*} p<0.01$. E and $\mathbf{F}$. Tumor weight (E) and volume (F) were statistically analyzed after tumors were isolated from mice at day $32 .{ }^{*} p<$ 0.01 , student $t$ test. 
lamellipodia formation, cell migration and tumorigenesis, at least in our model system, A549 cells. However, we do not rule out the possibility of the involvement of integrin $\alpha_{v} \beta_{3}$ in those cellular events in other system.

Because cell-surface CD44 did not appeared in the lamellipodia of growth factor-stimulated cells after antibody neutralization of $\mathrm{gClqR}, \mathrm{CD} 44$ might be involved in gClqR-mediated lamellipodia formation. Interestingly, both gC1qR and CD44 are critical components for lamellipodia formation, because they interact with hyaluronic acid and regulate various RTKs $[3,39,40]$. In addition, there has been a suggestion for a molecular interaction between $\mathrm{gC} 1 \mathrm{qR}$ and CD44 [6, 41], speculating that molecular association of $\mathrm{gC1qR}$ with CD44 is necessary for lamellipodia formation and RTK activation. However, CD44 knockdown increases PDGF signaling whereas antibody neutralization of cellsurface gC1qR did not change PDGF signaling [42]. This discrepancy of CD44 and $\mathrm{gClqR}$ in PDGF signaling challenges the relationship between $\mathrm{CD} 44$ and $\mathrm{gClqR}$ in the regulation of RTK activation and molecular mechanisms of $\mathrm{gClqR}$ in RTK regulation should be carefully investigated without molecular association of gC1qR with CD44.

\section{MATERIALS AND METHODS}

\section{Cell lines and cell culture}

A549, HeLa, MDA-MB-231 and MCF7 cells were obtained from the American Type Culture Collection (ATCC, VA, USA) and HUVEC from Lonza Inc. (Basel, Switzerland). MCF7, HeLa and hybridoma cells were cultured in DMEM (Hyclone, UT, USA) with 10\% fetal bovine serum (FBS). A549 and MDA-MB-231 cells were maintained in RPMI (Hyclone, UT, USA) 1640 media containing 10\% FBS and HUVEC in EGM-2 (Lonza, Basel, Switzerland).

\section{Antibodies and reagents}

Monoclonal mouse anti-gC1qR antibodies (3D9 and others) were generated using full-length recombinant $\mathrm{gC} 1 \mathrm{qR}$ as an antigen. Anti-phospho-Akt, FAK, phosphoFAK, phospho-IGFR, VEGF, phospho-VEGF, phosphoPDGF, PDGF and PDH antibodies were purchased from Cell Signaling (CA, USA) and anti-GAPDH, EGFR, Erk, CD44, flotilin-1, phospho-EGFR and phospho-Erk antibodies from Santa Cruz (CA, USA). Alexa 488- and 555-conjugated secondary antibodies were purchased from Invitrogen (CA, USA). Human recombinant IGF-1, PDGF and VEGF were purchased from R\&D Systems $(M N$, USA) and EGF from Sigma (MO, USA).

\section{Preparation of monoclonal mouse anti-gC1qR antibody}

Monoclonal mouse anti-gClqR antibodies were raised using recombinant full-length human $\mathrm{gClqR}$ as an antigen.
A single-cell hybridoma was isolated with the ClonaCell-HY Hybridoma Cloning Kit (Stemcell technologies, BC, Canada) according to the manufacturer's instruction and screened by ELISA with recombinant $\mathrm{gC} 1 \mathrm{qR}$. Monoclonal antibodies were purified from each hybridoma clone using protein-G affinity chromatography (GE healthcare). Specifically, 3D9 mAb was purified from the media of hybridoma cells (3D9), which were cultured in $8 \mathrm{mM}$ L-glutamine (Sigma, MO, USA)-containing CD hybridoma medium (NY, USA) in Integra CL 1000 flasks (Integra Biosciences, NH, USA) following the manufacturer's instructions.

\section{Immunoblotting and immunofluorescence}

Cells were washed three times with cold PBS and lysed with RIPA buffer (25 mM Tris-HCL. pH 7.6, 150 $\mathrm{mM} \mathrm{NaCl}, 1 \% \mathrm{NP}-40,1 \%$ sodium deoxycholate and $0.1 \%$ SDS) containing protease inhibitors (GenDEPOT, TX, USA) and phosphatase inhibitors (GenDEPOT, TX, USA). The cell lysates were separated using SDS-PAGE and transferred to a nitrocellulose membrane. After blocking with $5 \%(\mathrm{w} / \mathrm{v})$ BSA or skim milk for $1 \mathrm{~h}$ in Tris-buffered saline (TBS) with $0.05 \%$ Tween 20 , primary antibodies were incubated for $1 \mathrm{~h}$ at room temperature or overnight at $2-8^{\circ} \mathrm{C}$. Next, secondary antibodies were incubated for $1 \mathrm{~h}$ and the target proteins were detected with x-ray film in a darkroom.

For immunofluorescence, target cells were fixed with $3.7 \%$ para-formaldehyde for $15 \mathrm{~min}$, permeabilized in $0.1 \%$ Triton X-100 for 5 min and blocked with PBS containing 5\% BSA for $1 \mathrm{~h}$. Primary and secondary antibodies were incubated for $1 \mathrm{~h}$ for immunofluorescence. The fluorescence-labeled cells were analyzed with a Zeiss LSM700 Meta confocal microscope (Carl Zeiss, Germany).

\section{Cell proliferation}

For cell proliferation assay, $2.0 \times 10^{4}$ cells were dispensed in a 6-well plate and incubated for $12 \mathrm{~h}$. After the serum starvation for $18 \mathrm{~h}$, the cells were further incubated with FBS (10\%)-, EGF (50 ng/mL)- or IGF$1(100 \mathrm{ng} / \mathrm{mL})$-containing RPMI in the presence of 10 $\mu \mathrm{g} / \mathrm{mL}$ of mock IgG or $\mathrm{mAb} \mathrm{gClqR}$, respectively for 4 days.

\section{Trans-well migration assay}

First, $5 \times 10^{4}$ cells were serum-starved for $18 \mathrm{~h}$, trypsinized for $4 \mathrm{~min}$, pretreated with $10 \mu \mathrm{g} / \mathrm{mL}$ of mock IgG or anti-gC1qR antibodies for $30 \mathrm{~min}$ at $4^{\circ} \mathrm{C}$ and transferred to the upper chamber of a Boyden chamber. The cells were further incubated for $18 \mathrm{~h}$ after FBS (10\%)-, EGF (50 ng/mL)- or IGF-1 (100 ng/mL)-containing media $(600 \mu \mathrm{L})$ were added to the lower chamber. The cells on the membrane were fixed with $3.7 \%$ formaldehyde for 20 min and stained with $0.1 \%$ crystal violet for $20 \mathrm{~min}$. Cell 
migration number was counted after removing the upper chamber cells with a cotton swab.

\section{Wound-healing assay}

Wound healing assay was performed as previously described[43]. Cells were grown to confluency, serumstarved for $18 \mathrm{~h}$ and pretreated with $10 \mu \mathrm{g} / \mathrm{mL}$ of mock IgG or anti-gClqR antibodies for $4 \mathrm{~h}$. The cells were scraped with a sterile micropipette tip and stimulated with FBS (10\%), EGF (50 ng/mL) or IGF-1 (100 ng/mL) for 12 or $30 \mathrm{~h}$ in the presence of $10 \mu \mathrm{g} / \mathrm{mL}$ of mock IgG or anti-gC1qR antibody. The cells were fixed with $3.7 \%$ formaldehyde for $20 \mathrm{~min}$ and stained with $0.1 \%$ crystal violet for $20 \mathrm{~min}$. Images for migrated cells were captured with a microscope.

\section{Subcellular fractionation}

The plasma membrane was isolated according to Hubbard et al. (1983) [44], with minor modifications. Cells were harvested with cold TES buffer $(20 \mathrm{mM}$ Tris $\mathrm{HCl}$, $\mathrm{pH}$ 7.4, 1 mM EDTA, 8.7\% sucrose) and homogenized with a glass homogenizer. The homogenized samples were centrifuged at 17,500 rpm in a SW41Ti (Beckman) for $30 \mathrm{~min}$ at $4^{\circ} \mathrm{C}$. The pellets were re-suspended with TES buffer, loaded on a $38 \%$ sucrose cushion and centrifuged at $100,000 \mathrm{x}$ g for $30 \mathrm{~min}$ at $4^{\circ} \mathrm{C}$. The plasma membranes were isolated from a band between $8.7 \%$ and $38 \%$ sucrose and mitochondria from a band between $38 \%$ and $50 \%$ sucrose. The isolated samples were re-suspended with TES buffer and centrifuged at $17500 \mathrm{rpm}$ in a SW41Ti rotor for $30 \mathrm{~min}$ at $4^{\circ} \mathrm{C}$ for 2 times. The pellets were lysed with RIPA buffer for immunoblotting.

\section{In vitro tube formation assay}

In vitro tube formation assay were performed according to Arnaouova et al. [45]. HEVEC were serumstarved in $0.2 \%$ FBS-containing EBM-2 media (Lonza, Basel, Switzerland) for $18 \mathrm{~h}$. The cells were dispensed into Matrigel-coated culture plates with EGM-2 media in the presence of $200 \mu \mathrm{g} / \mathrm{mL}$ of mock IgG or anti-gClqR antibody and incubated for $18 \mathrm{~h}$. The cells were fixed with $3.7 \%$ formaldehyde and cell images were taken under a microscope.

\section{Animal study and in vivo tumorigenesis study}

Five-week-old female BALB/c nude mice were purchased from Orient Bio Inc. (Seongnam, South Korea) and maintained at $22 \pm 2{ }^{\circ} \mathrm{C}$ and $50 \pm 10 \%$ humidity under a $12 \mathrm{~h}$ light: $12 \mathrm{~h}$ dark regimen. The Institutional Animal Care and Use Committee of the Korea Institute of Radiological and Medical Science approved the studies, which were performed under the guidelines for the care and use of laboratory animals. A549 cells $\left(3 \times 10^{6}\right)$ were subcutaneously injected into the right foreleg of mice $(n=$ 5/group). One hundred microliters of PBS or anti-gC1qR antibody $(10 \mathrm{mg} / \mathrm{kg})$ was intraperitoneally injected twice weekly when palpable tumor developed. Tumors were measured twice weekly for 32 days and tumor size was calculated according to the following equation: $\mathrm{V}=0.5 \times$ (width ${ }^{2} \times$ length).

\section{ACKNOWLEDGMENTS}

This work was supported by grants awarded to Y.-G. Ko from the National Research Foundation (20110017562 and 2015R1A5A1009024) and to J.-S. Lee from the Nuclear Research and Development Program (Grant No. 2012M2B2B1055637) of the National Research Foundation (NRF) of Korea. This work was also partially supported by a Korea University grant (to Y.-G. Ko).

\section{CONFLICTS OF INTEREST}

The authors declare no conflicts of interest.

\section{REFERENCES}

1. Krainer AR, Mayeda A, Kozak D, Binns G. Functional expression of cloned human splicing factor SF2: homology to RNA-binding proteins, U1 70K, and Drosophila splicing regulators. Cell. 1991; 66:383-394.

2. Ghebrehiwet B, Lim BL, Peerschke EI, Willis AC, Reid $\mathrm{KB}$. Isolation, cDNA cloning, and overexpression of a $33-\mathrm{kD}$ cell surface glycoprotein that binds to the globular "heads" of C1q. J Exp Med. 1994; 179:1809-1821.

3. Kim KB, Yi JS, Nguyen N, Lee JH, Kwon YC, Ahn BY, Cho H, Kim YK, Yoo HJ, Lee JS, Ko YG. Cell-surface receptor for complement component $\mathrm{C} 1 \mathrm{q}(\mathrm{gCl} \mathrm{qR})$ is a key regulator for lamellipodia formation and cancer metastasis. J Biol Chem. 2011; 286:23093-23101.

4. Kim KB, Kim BW, Choo HJ, Kwon YC, Ahn BY, Choi JS, Lee JS, Ko YG. Proteome analysis of adipocyte lipid rafts reveals that $\mathrm{gClqR}$ plays essential roles in adipogenesis and insulin signal transduction. Proteomics. 2009; 9:2373-2382.

5. Fogal V, Zhang L, Krajewski S, Ruoslahti E. Mitochondrial/ cell-surface protein $\mathrm{p} 32 / \mathrm{gC} 1 \mathrm{qR}$ as a molecular target in tumor cells and tumor stroma. Cancer Res. 2008; 68:7210-7218.

6. Braun L, Ghebrehiwet B, Cossart P. gC1q-R/p32, a C1qbinding protein, is a receptor for the InlB invasion protein of Listeria monocytogenes. EMBO J. 2000; 19:1458-1466.

7. Mahdi F, Shariat-Madar Z, Todd RF, 3rd, Figueroa CD, Schmaier AH. Expression and colocalization of cytokeratin 1 and urokinase plasminogen activator receptor on endothelial cells. Blood. 2001; 97:2342-2350.

8. Gupta S, Batchu RB, Datta K. Purification, partial characterization of rat kidney hyaluronic acid binding 
protein and its localization on the cell surface. Eur J Cell Biol. 1991; 56:58-67.

9. Lim BL, Reid KB, Ghebrehiwet B, Peerschke EI, Leigh LA, Preissner KT. The binding protein for globular heads of complement C1q, gC1qR. Functional expression and characterization as a novel vitronectin binding factor. J Biol Chem. 1996; 271:26739-26744.

10. Peerschke EI, Reid KB, Ghebrehiwet B. Identification of a novel 33-kDa C1q-binding site on human blood platelets. J Immunol. 1994; 152:5896-5901.

11. Ghebrehiwet B, CebadaMora C, Tantral L, Jesty J, Peerschke EI. gC1qR/p33 serves as a molecular bridge between the complement and contact activation systems and is an important catalyst in inflammation. Adv Exp Med Biol. 2006; 586:95-105.

12. $\mathrm{Yu} \mathrm{G}$, Wang J. Significance of hyaluronan binding protein (HABP1/P32/gC1qR) expression in advanced serous ovarian cancer patients. Exp Mol Pathol. 2013; 94:210-215.

13. Chen YB, Jiang CT, Zhang GQ, Wang JS, Pang D. Increased expression of hyaluronic acid binding protein 1 is correlated with poor prognosis in patients with breast cancer. J Surg Oncol. 2009; 100:382-386.

14. Zhao J, Liu T, Yu G, Wang J. Overexpression of HABP1 correlated with clinicopathological characteristics and unfavorable prognosis in endometrial cancer. Tumour Biol. 2015; 36:1299-1306.

15. Aman A, Piotrowski T. Cell migration during morphogenesis. Dev Biol. 2010; 341:20-33.

16. Bernards R. Cancer: cues for migration. Nature. 2003; 425:247-248.

17. Friedl $\mathrm{P}$, Wolf $\mathrm{K}$. Tumour-cell invasion and migration: diversity and escape mechanisms. Nat Rev Cancer. 2003; 3:362-374.

18. Yamaguchi H, Wyckoff J, Condeelis J. Cell migration in tumors. Curr Opin Cell Biol. 2005; 17:559-564.

19. Ren Y, Cao B, Law S, Xie Y, Lee PY, Cheung L, Chen Y, Huang X, Chan HM, Zhao P, Luk J, Vande Woude G, Wong J. Hepatocyte growth factor promotes cancer cell migration and angiogenic factors expression: a prognostic marker of human esophageal squamous cell carcinomas. Clin Cancer Res. 2005; 11:6190-6197.

20. Boilly B, Vercoutter-Edouart AS, Hondermarck H, Nurcombe V, Le Bourhis X. FGF signals for cell proliferation and migration through different pathways. Cytokine Growth Factor Rev. 2000; 11:295-302.

21. Selfors LM, Schutzman JL, Borland CZ, Stern MJ. soc-2 encodes a leucine-rich repeat protein implicated in fibroblast growth factor receptor signaling. Proc Natl Acad Sci U S A. 1998; 95:6903-6908.

22. Le Clainche C, Carlier MF. Regulation of actin assembly associated with protrusion and adhesion in cell migration. Physiol Rev. 2008; 88:489-513.

23. Machesky LM. Lamellipodia and filopodia in metastasis and invasion. FEBS Lett. 2008; 582:2102-2111.
24. Baumgartner M, Sillman AL, Blackwood EM, Srivastava J, Madson N, Schilling JW, Wright JH, Barber DL. The Nck-interacting kinase phosphorylates ERM proteins for formation of lamellipodium by growth factors. Proc Natl Acad Sci U S A. 2006; 103:13391-13396.

25. Oliferenko S, Kaverina I, Small JV, Huber LA. Hyaluronic acid (HA) binding to CD44 activates Rac1 and induces lamellipodia outgrowth. J Cell Biol. 2000; 148:1159-1164.

26. Van Haastert PJ, Devreotes PN. Chemotaxis: signalling the way forward. Nat Rev Mol Cell Biol. 2004; 5:626-634.

27. Feng X, Tonnesen MG, Peerschke EI, Ghebrehiwet B. Cooperation of $\mathrm{C} 1 \mathrm{q}$ receptors and integrins in $\mathrm{C} 1 \mathrm{q}-$-mediated endothelial cell adhesion and spreading. J Immunol. 2002; 168:2441-2448.

28. Joseph K, Tholanikunnel BG, Ghebrehiwet B, Kaplan AP. Interaction of high molecular weight kininogen binding proteins on endothelial cells. Thromb Haemost. 2004; 91:61-70.

29. Muta T, Kang D, Kitajima S, Fujiwara T, Hamasaki N. p32 protein, a splicing factor 2-associated protein, is localized in mitochondrial matrix and is functionally important in maintaining oxidative phosphorylation. J Biol Chem. 1997; 272:24363-24370.

30. Yagi M, Uchiumi T, Takazaki S, Okuno B, Nomura M, Yoshida S, Kanki T, Kang D. p32/gC1qR is indispensable for fetal development and mitochondrial translation: importance of its RNA-binding ability. Nucleic Acids Res. 2012; 40:9717-9737.

31. Fausther-Bovendo H, Vieillard V, Sagan S, Bismuth G, Debre P. HIV gp41 engages gC1qR on CD4+ T cells to induce the expression of an NK ligand through the PIP3/ H2O2 pathway. PLoS Pathog. 2010; 6:e1000975.

32. Choi Y, Kwon YC, Kim SI, Park JM, Lee KH, Ahn BY. A hantavirus causing hemorrhagic fever with renal syndrome requires $\mathrm{gC} 1 \mathrm{qR} / \mathrm{p} 32$ for efficient cell binding and infection. Virology. 2008; 381:178-183.

33. Laakkonen P, Akerman ME, Biliran H, Yang M, Ferrer F, Karpanen T, Hoffman RM, Ruoslahti E. Antitumor activity of a homing peptide that targets tumor lymphatics and tumor cells. Proc Natl Acad Sci U S A. 2004; 101:9381-9386.

34. Prakash M, Kale S, Ghosh I, Kundu GC, Datta K. Hyaluronan-binding protein 1 (HABP1/p32/gC1qR) induces melanoma cell migration and tumor growth by NF-kappa B dependent MMP-2 activation through integrin alpha(v) beta(3) interaction. Cell Signal. 2011; 23:1563-1577.

35. Kaul R, Saha P, Saradhi M, Prasad RL, Chatterjee S, Ghosh I, Tyagi RK, Datta K. Overexpression of hyaluronan-binding protein 1 (HABP $1 / \mathrm{p} 32 / \mathrm{gC} 1 \mathrm{qR})$ in HepG2 cells leads to increased hyaluronan synthesis and cell proliferation by up-regulation of cyclin D1 in AKTdependent pathway. J Biol Chem. 2012; 287:19750-19764.

36. Guo W, Giancotti FG. Integrin signalling during tumour progression. Nat Rev Mol Cell Biol. 2004; 5:816-826. 
37. Soung YH, Clifford JL, Chung J. Crosstalk between integrin and receptor tyrosine kinase signaling in breast carcinoma progression. BMB Rep. 2010; 43:311-318.

38. Guo L, Zhang F, Cai Y, Liu T. Expression profiling of integrins in lung cancer cells. Pathol Res Pract. 2009; 205:847-853.

39. Ponta H, Sherman L, Herrlich PA. CD44: from adhesion molecules to signalling regulators. Nat Rev Mol Cell Biol. 2003; 4:33-45.

40. Orian-Rousseau V. CD44, a therapeutic target for metastasising tumours. Eur J Cancer. 2010; 46:1271-1277.

41. Jung C, Matzke A, Niemann HH, Schwerk C, Tenenbaum T, Orian-Rousseau V. Involvement of CD44v6 in InlBdependent Listeria invasion. Mol Microbiol. 2009; 72:1196-1207.
42. Porsch H, Mehic M, Olofsson B, Heldin P, Heldin CH. Platelet-derived growth factor beta-receptor, transforming growth factor beta type I receptor, and CD44 protein modulate each other's signaling and stability. J Biol Chem. 2014; 289:19747-19757.

43. Lee SH, Paek AR, Yoon K, Kim SH, Lee SY, You HJ. Tight junction protein 1 is regulated by transforming growth factor-beta and contributes to cell motility in NSCLC cells. BMB Rep. 2015; 48:115-120.

44. Hubbard AL, Ma A. Isolation of rat hepatocyte plasma membranes. II. Identification of membrane-associated cytoskeletal proteins. J Cell Biol. 1983; 96:230-239.

45. Arnaoutova I, Kleinman HK. In vitro angiogenesis: endothelial cell tube formation on gelled basement membrane extract. Nat Protoc. 2010; 5:628-635. 